\title{
Allocating Tradable Emissions Permits Based on the Proportional Allocation Concept to Achieve a Low-Carbon Economy
}

\author{
Qianzhi Dai, ${ }^{1}$ Yongjun Li, ${ }^{1}$ Qiwei Xie, ${ }^{2,3}$ and Liang Liang' \\ ${ }^{1}$ School of Business, University of Science and Technology of China, Hefei, Anhui 230026, China \\ ${ }^{2}$ Department of Electronics and Information, Toyota Technological Institute, Nagoya 468-8511, Japan \\ ${ }^{3}$ Institute of Automation, Chinese Academy of Sciences, Beijing 100190, China \\ Correspondence should be addressed to Qiwei Xie; qwxie2012@gmail.com
}

Received 17 December 2013; Accepted 19 March 2014; Published 16 April 2014

Academic Editor: Xiaodong Lin

Copyright ( 2014 Qianzhi Dai et al. This is an open access article distributed under the Creative Commons Attribution License, which permits unrestricted use, distribution, and reproduction in any medium, provided the original work is properly cited.

\begin{abstract}
A key issue within the emissions trading system is how tradable emissions permits (TEPs) are initially allocated among a set of entities. This study proposes an approach based on the proportional allocation concept to allocate TEPs among a set of decision making units (DMUs). We firstly deduce a TEP allocation set based on the rule that the TEPs allocated to DMUs should be proportional to their environmental contribution. We then obtain the allocation intervals of DMUs from the set, expressing the allocation as the convex combination between the upper and the lower bound. Finally, we define the satisfaction degree as the coefficient of the convex combination, and propose an algorithm based on the max-min fairness of satisfaction degrees to obtain a unique TEP allocation plan. To illustrate our approach, we provide the example of how TEPs are allocated among 30 provincial administrative regions in China. Our findings indicate that our allocation method can be helpful for achieving a saving in energy consumption and reducing emissions. In addition, from the data envelopment analysis perspective, the TEP allocation set can ensure that both each individual DMU and the organization as a whole become efficient under a common set of variable weights.
\end{abstract}

\section{Introduction}

The greenhouse gas (GHG) is thought to be the main cause of global warming and climate change. With fighting against anthropogenic global warming, the low-carbon economy was born. The Conference of the Parties (COP) 17 actually eliminates the differential treatment for developed and developing countries in the Kyoto Protocol and lays the groundwork for establishing a worldwide emissions trading system (ETS). In practice, an ETS in the European Union (EU) has operated since 2005. In China, the first carbon emission rights exchange was piloted in Shenzhen in 2013. Throughout this process, the central question emerged of how tradable emissions permits (TEPs) are initially allocated among different entities.

Numerous studies have been conducted to support the work of stabilizing GHG concentrations. Enforcing pollution taxes (e.g., $[1,2]$ ) is a cost-effectiveness approach; that is, a uniform pollution tax can induce a specified pollution reduction with minimum cost because it entails marginal abatement costs among the different sources [3]. However, it is difficult to obtain perfect information about marginal abatement cost functions. Thus, environmental taxes are not the most common mode of environmental regulation, even though they exist in Europe [4].

The TEP is another cost-effectiveness approach that can help to determine the right price of emissions permits in the market. In terms of the Coase Theorem [5], the initial TEP allocation does not affect the final equilibrium when there are no transaction costs [6]. However, there are different types of transaction costs arising from incomplete information or contracting costs in practice, which limit the applicability of the Coase Theorem (e.g., $[7,8])$.

Exogenous criteria, output-based allocation (OBA), and auction are three common methodologies of initial TEP allocation [9]. Exogenous criteria and OBA refer to free 
distributions. One of most common exogenous criteria is grandfathering (GF), which is a non-revenue-raising approach based on a historic evaluation of performance [9]. There are some potentially questionable effects of GF, such as overcompensating firms and leading to windfall profits (e.g., $[10,11])$, market distortions [12], and reducing the incentive for regulated firms to develop environmental innovations [9], among others. Subsequently, GF has developed from a one-off allowance allocation to the allocation of periodic allowances [13]. Compared with the one-off GF allocation, periodic allowances allocation can provide fairer treatment for existing firms and new entrants. Moreover, it can also decrease the risk of existing firms relocating their polluting activities to nonregulated areas in order to keep and profit from their allowances. However, this approach has some drawbacks, such as greater complexity in administration and, consequently, higher administrative costs.

Output-based uniform benchmark [14] generates the allocation primarily based on common output and sector benchmarks. It allows for dynamically updating allowances, which then provides firms with an incentive to influence their future allocation by changing their behavior.

The third common mode of TEP allocation, auction, allocates permits to the highest bidders (e.g., $[15,16])$. Economists have highlighted several advantages of the auction mode [12], which include promoting innovation [17], improving administrative transparency and the perception of fairness [18], reducing the overall cost of the regulation, and increasing the efficiency of the economy [19]. However, certain challenges mean that the approach is rarely used in practice, such as the technical complexities of designing efficient multiunit auctions and strong opposition from related firms.

The above three common methods consider the TEP allocation problem. There are also many other methods from different perspectives studying the related problems, such as [20-22]. Therefore, the TEP allocation problem is a hot research issue in many subjects.

Our proposed approach is different from traditional TEP allocation methods. This paper allocates the TEP quotas among a set of decision making units (DMUs) under the rule that the TEP allocated to DMUs should be proportional to their environmental contribution. In general, the resource consumption levels of DMUs for generating one unit of output vary owing to their different economic structures and low-carbon technology levels. We define the environmental contribution of each DMU as their weighted sum of outputs minus their weighted sum of inputs. Based on the allocation rule, we first deduce a TEP allocation set that can ensure both the entire organization and each individual DMU efficient under a common set of variable weights. We then obtain the allocation intervals of DMUs from the TEP allocation set. The optimal allocation must be generated from the allocation intervals. That is, the allocation plan can be expressed as the convex combination between the upper and the lower bound. We define the satisfaction degree as the coefficient of the convex combination. Finally, we generate a unique TEP allocation plan under the max-min fairness of satisfaction degrees. Our findings indicate that this allocation rule can guide DMUs to improve their performance.
The implications of these findings may be helpful to encourage the development and application of low-carbon technologies for achieving a saving in energy consumption and a reduction in emissions.

The rest of this study is organized as follows. In Section 2, we propose our TEP allocation approach. In Section 3, an example of allocating the TEP among 30 provincial administrative regions in China is employed to illustrate our approach. Conclusions are given in Section 4.

\section{Methodology}

Suppose that there are $n$ independent rational participants (DMUs), and $\mathrm{DMU}_{j}(j=1,2, \ldots, n)$ consumes $m$ resources (i.e., inputs) $x_{i j}(i=1,2, \ldots, m)$ to generate $s$ outputs $y_{r j}(r=$ $1,2, \ldots, s)$.

As mentioned above, the environmental contribution of each DMU varies in the production process. To convert different outputs and resources into a common platform, we assign unknown weights $\left(\mu_{r}, v_{i}, \forall r, i\right)$ for them. Therefore, we can define the environmental contribution of $\mathrm{DMU}_{d}(d \in$ $\{1,2, \ldots, n\})$ as

$$
\Delta_{d}=\sum_{r=1}^{s} \mu_{r} y_{r d}-\sum_{i=1}^{m} v_{i} x_{i d}, \quad v_{i}, \mu_{r} \geq 0, \forall i, r,
$$

where $\Delta_{d}$ is the environmental contribution of $\mathrm{DMU}_{d}$. Formula (1) indicates that the environmental contribution is directly proportional to outputs and inversely proportional to inputs. Besides, the different units of inputs and outputs would not have any effect when calculating the environmental contribution $\Delta_{d}$. It is because that $\left(\mu_{r}, v_{i}, \forall r, i\right)$ is a common set of weights for all DMUs. For example, suppose that there are several paper mills (DMUs) that consume three inputs (water, labor, and capital) to produce one output (paper). If there are two data sets, one set is collected based on the units: water in tons, labor in persons, capital in Yuan, and output in tons, and the other set is collected based on the units: water as ten tons, labor as one hundred persons, capital as one million Yuan, and output as thousand tons, then both of the data sets could obtain the same $\Delta_{d}$ based on our proposed approach (see the algorithm on the next page). This is because, to the first data set, suppose that the optimal weight set is $\left(\mu_{1}^{*}, v_{1}^{*}, v_{2}^{*}, v_{3}^{*}\right)$; then $\left((1 / 1000) \mu_{1}^{*},(1 / 10) v_{1}^{*},(1 / 100) v_{2}^{*},\left(1 / 10^{6}\right) v_{3}^{*}\right)$ must be also an optimal weight set of the second data set, which means that the value of $\Delta_{d}$ is unchanged.

To achieve the goal of stabilizing GHG concentrations, we consider that the TEP allocated to each DMU should be proportional to their environmental contribution. As Bertsimas et al. [23] said, the proportional fairness is a well-accepted and axiomatically justified notion. Besides the proportional fairness, another well-accepted fairness is the max-min fairness, which would be applied in our approach later. The concept of the proportional fairness is well-applied in many DEA-based allocation methods, such as [24-27]. 
Based on the allocation rule, we can get

$$
\begin{aligned}
& \Omega=\{\left(P_{1}, \ldots, P_{n}\right) \mid P_{j} \\
&= \frac{\left(\sum_{r=1}^{s} \mu_{r} y_{r j}-\sum_{i=1}^{m} v_{i} x_{i j}\right)}{\sum_{j=1}^{n}\left(\sum_{r=1}^{s} \mu_{r} y_{r j}-\sum_{i=1}^{m} v_{i} x_{i j}\right)}, \\
&\left.P_{j}, \mu_{r}, v_{i} \geq 0, \forall r, i, j\right\},
\end{aligned}
$$

where $P_{j}$ is the TEP proportion allocated to $\mathrm{DMU}_{j}$. Therefore, a DMU, who wants to increase his TEP allocation proportion, would be willing to consume minimal inputs to generate maximal outputs.

Remark 1. Formula (2) can allocate the TEP in a way which provides incentives to achieve the energy consumption saving and emissions reduction.

Theorem 2. If the evaluation indicator is one-dimensional $\left(y_{j}\right.$ or $x_{j}$ ), the TEP allocation plan based on formula (2) must be a unique proportional allocation.

Theorem 2 states that formula (2) would be equivalent to the simple proportional allocation method in the onedimensional input (or output) case. The simple proportional allocation method has some good advantages, such as simple form and being easily understood. It has been widely applied in practice, such as finance and accounting. Besides, the unique TEP allocation plan can also avoid the controversy in the implementation process.

Then, we study how to allocate the TEP among a set of DMUs in the case of multidimensional evaluation indicators. Let $t=1 / \sum_{j=1}^{n}\left(\sum_{r=1}^{s} \mu_{r} y_{r j}-\sum_{i=1}^{m} v_{i} x_{i j}\right), u_{r}=t \mu_{r}$ and $v_{i}=t v_{i}$; then we can convert formula (2) as follows:

$$
\begin{aligned}
& \Omega=\left\{\left(P_{1}, \ldots, P_{n}\right) \mid P_{j}\right. \\
& =\sum_{r=1}^{s} u_{r} y_{r j}-\sum_{i=1}^{m} v_{i} x_{i j}, \\
& \left.\sum_{j=1}^{n} P_{j}=1, P_{j}, u_{r}, v_{i} \geq 0, \forall r, i, j\right\} \text {. }
\end{aligned}
$$

Because the environmental contributions of DMUs may be different, the TEP allocated to each DMU would vary. Consequently, we can obtain the upper and lower bound of the TEP proportion allocated to $\mathrm{DMU}_{d}$ as follows:

$$
\begin{array}{ll}
\operatorname{Max}(\text { or Min) } & P_{d} \\
\text { s.t. } & \text { formula (3), }
\end{array}
$$

where the decision variables are $u_{r}$ and $v_{i}(r=1, \ldots, s, i=$ $1, \ldots, m)$.

To obtain the minimal proportion $P_{d}$ of all DMUs, model (4) would be computed $n$ times by setting the subscript $d$ from 1 to $n$ every time. Similarly, model (4) also needs to be computed $n$ time to obtain the maximal proportion $\overline{P_{d}}$ of all DMUs. To each $P_{d}$ (or $\overline{P_{d}}$ ), it is obtained under a common set of weights every time. But, to $\overline{P_{j}}\left(\right.$ or $\left.\overline{P_{j}}\right)(j=1,2, \ldots, n)$, they are not obtained under a common set of weights; therefore it is very hard to get $\sum_{j=1}^{n} \overline{P_{j}}=1$.

Donate the TEP proportion interval of $\mathrm{DMU}_{d}$ by $\left[P_{d}, \overline{P_{d}}\right]$. If the upper and lower bound of each DMU are equal, that is, $P_{j}=\overline{P_{j}}$ (for all $j$ ), then the allocation plan would be determined uniquely. Unfortunately, they are often not the same. Because each DMU is rational, then $\mathrm{DMU}_{d}$ would be selfish to receive the maximal TEP proportion $\overline{P_{d}}$ but unwilling to accept the minimal TEP proportion $P_{d}$. But it would cause that the sum of $\overline{P_{j}}$ is very likely larger than 1 (i.e., $\sum_{j=1}^{n} \overline{P_{j}}>1$ ); that is, the TEP demand is greater than the TEP supply. Accordingly, we should find a compromise way to allocate the TEP.

Because $P_{d} \in\left[P_{d}, \overline{P_{d}}\right]$, we can express the allocation plan as the convex combination between the upper bound and the lower bound; that is, $P_{d}=\lambda_{d} \overline{P_{d}}+\left(1-\lambda_{d}\right) P_{d}, \lambda_{d} \geq 0, \forall d$. It can be rewritten as follows:

$$
\lambda_{d}=\frac{\left(P_{d}-\underline{P_{d}}\right)}{\left(\overline{P_{d}}-\underline{P_{d}}\right)}, \quad \forall d,
$$

where $\lambda_{d} \in[0,1] . \lambda_{d}$ can be seen as the satisfaction degree of $\mathrm{DMU}_{d}$. That is to say, if $\mathrm{DMU}_{d}$ afforded the maximal TEP proportion $\overline{P_{d}}$, he would be satisfied with the allocation plan completely and his satisfaction degree would be $\lambda_{d}=1$. On the contrary, his satisfaction degree would be $\lambda_{d}=0$. Thus, the psychology perception of DMUs to the TEP allocation can be quantificationally measured.

To obtain a unique TEP allocation plan, we consider the max-min fairness of satisfaction degrees. There are multiple interpretations of the fairness, and no single concept is universally accepted. It is adopted in this study because it can reflect the Rawlsian justice and is widely applied in practice [23]. Accordingly, we can get the TEP allocation model as follows:

$$
\begin{array}{ll}
\operatorname{Max}_{u, v} \min _{1 \leq d \leq n} & \lambda_{d}=\frac{\left(P_{d}-\underline{P_{d}}\right)}{\left(\overline{P_{d}}-\underline{P_{d}}\right)} \\
\text { s.t. } & \text { formula }(3) .
\end{array}
$$

Model (6) is a multiobjective programming. Let $\min _{1 \leq d \leq n} \lambda_{d}=\beta$; then it can be transformed into the following model:

$$
\begin{array}{ll}
\operatorname{Max}_{u, v} & \beta \\
\text { s.t. } & \lambda_{j}=\frac{P_{j}-\underline{P_{j}}}{\overline{P_{j}}-\underline{P_{j}}} \geq \beta, \quad \forall j, \\
& \text { formula (3). }
\end{array}
$$

An algorithm is provided to generate a unique TEP proportion allocation plan $\left(P_{1}^{*}, P_{2}^{*}, \ldots, P_{n}^{*}\right)$. 
Step 1. Let $l=1$ and denote the optimal solution to model (7) by $\left(\lambda_{1 j}^{*}, u_{1 r}^{*}, v_{1 i}^{*}, P_{1 j}^{*}, \forall r, i, j\right)$. If $\lambda_{j}=\left(P_{1 j}^{*}-P_{j}\right) /\left(\overline{P_{j}}-P_{j}\right)=\beta_{1}^{*}$, then denote the DMU set with the same satisfaction degree $\beta_{1}^{*}$ as

$$
\begin{aligned}
& J_{1}=\left\{j \mid \lambda_{j}=\beta_{1}^{*}, \forall j \in J_{0}\right\}, \\
& \text { then } P_{j}^{*}=P_{1 j}^{*}, \quad \forall j \in J_{1},
\end{aligned}
$$

and the number of DMUs with the same satisfaction degree $\beta_{1}^{*}$ is denoted by $n_{1}$. Then, other DMUs form a set denoted as

$$
J_{2}=\left\{j \mid \rho_{j}>\beta_{1}^{*}, \forall j \in J_{0}\right\} .
$$

Obviously, $J_{0}=J_{1} \cup J_{2}, J_{0}=\{1,2, \ldots, n\}$. If $n_{1}=$ $m+s$, then the procedure stops and the optimal solution $\left(\lambda_{1 j}^{*}, u_{1 r}^{*}, v_{1 i}^{*}, P_{1 j}^{*}, \forall r, i, j\right)$ is unique. If $n_{1}<m+s$, then go to Step 2.

Step 2. Set $l=l+1$; solve the following general model:

$$
\begin{gathered}
\beta_{l}^{*}=\operatorname{Max}_{u, v} \beta, \\
\text { s.t. } \quad \lambda_{j}=\beta_{1}^{*}, \quad j \in J_{1} ; \\
\lambda_{j}=\beta_{2}^{*}, \quad j \in J_{3} ; \\
\vdots \\
\lambda_{j}=\beta_{l-1}^{*}, \quad j \in J_{2 l-3} ; \\
\lambda_{j}=\frac{\left(\overline{P_{j}}-\underline{P_{j}}\right)}{\left(\overline{P_{j}}-\underline{P_{j}}\right)} \geq \beta, \quad j \in J_{2 l-2},
\end{gathered}
$$

formula (3).

We can get $\left(\lambda_{l j}^{*}, u_{l r}^{*}, v_{l i}^{*}, P_{l j}^{*}, \forall r, i, j\right)$ from model (10), and $J_{2 l-2}$ can be divided into two subsets:

$$
\begin{gathered}
J_{2 l-1}=\left\{j \mid \rho_{j}=\beta_{l}^{*}, \forall j \in J_{2 l-2}\right\}, \\
\text { then } R_{j}^{*}=R_{l j}^{*}, \quad \forall j \in J_{2 l-1}, \\
J_{2 l}=\left\{j \mid \rho_{j}>\beta_{l}^{*}, \forall j \in J_{2 l-2}\right\}=J_{2 l-2}-J_{2 l-1},
\end{gathered}
$$

and the number of DMUs with the same satisfaction degree $\beta_{l}^{*}$ is denoted by $n_{l}$. If $n_{1}+n_{2}+\cdots n_{l}<m+s$, then repeat Step 2. If $n_{1}+n_{2}+\cdots n_{l}=m+s$, the procedure stops and the optimal solution $\left(\lambda_{l j}^{*}, u_{l r}^{*}, v_{l i}^{*}, P_{l j}^{*}, \forall r, i, j\right)$ is also unique.

As a result, the optimal TEP proportion allocation plan would be uniquely determined as $\left(P_{j}^{*}=P_{l j}^{*}, \forall j \in J_{0}\right)$.

There is an interesting coincidence that our approach has a similar mathematical form as the approach proposed by Li et al. [28]. They proposed an approach based on data envelopment analysis (DEA) [29] to allocate a fixed cost among a set of DMUs. Our research perspectives, research issues, and research insights are entirely different.
DEA is a well-established nonparametric approach for evaluating the performance of peer DMUs with multiple inputs and outputs. The fixed cost allocation problem is one of the important DEA applications. DEA methods allocate fixed costs from the perspective of the efficiency analysis. There are three typical allocation criteria in DEA allocation studies: efficiency invariance and Pareto minimality (e.g., [30, 31]), efficiency maximization (e.g., [28, 32]), and efficiency equalproportional increment [33].

Considering our approach from the perspective of DEA, we can get the following theorem, which is similar to Theorem 2 in Li et al. [28].

Theorem 3. Formula (3) can ensure that both each DMU and the entire whole organization are efficient under a common set of weights.

Proof. See the proof of Theorem 2 in Li et al. [28].

\section{Empirical Analysis}

In 2013, the carbon emission rights exchange, the first exchange of China, has piloted in Shenzhen. Establishing an ETS in China might be an irresistible trend. Therefore, we study how to allocate the TEP among a set of regions (DMUs) in advance. Certainly, our approach can also be used to allocate the TEP among a set of other entities, for example, companies and countries.

3.1. Select Evaluation Indicators. An important work is how to select appropriate evaluation indicators because it is directly related to relevant results. In general, all factors in production process can be considered as evaluation indicators. However, it is impossible to list all of these factors due to the limited rationality of human beings [34]. In previous literatures, a common practice is listing some typical factors as evaluation indicators. Therefore, this study selects two typical inputs and three typical outputs to measure the environmental contributions of DMUs. Certainly, it can also be amended in future practice.

Input 1 (I1). Total energy consumption by region (10000 tone standard coal): in the production process, DMUs consume energies to generate products. Thus, the energy consumption is an important factor that should be selected.

Input 2 (I2). Total volume of industrial waste gas emission (100 million cubic meters): the industrial waste gas emission is an undesirable product in productive process. In other words, it has a negative effect on the environmental contribution. In terms of the definition of the environmental contribution, it is considered as an input. Besides, if it is considered an output, DMUs who want to improve their environmental contributions would be willing to develop and apply low-carbon technologies to reduce their waste gas emission levels, which could be helpful to achieve the lowcarbon economy.

Output 1 (O1). Population (100 million): generally, DMUs with a larger population could be considered as making 
TABLE 1: Data set of 30 provincial administrative regions.

\begin{tabular}{|c|c|c|c|c|c|}
\hline \multirow{2}{*}{ Region } & \multicolumn{2}{|c|}{ Inputs } & \multicolumn{3}{|c|}{ Outputs } \\
\hline & I1 & $\mathrm{I} 2$ & $\mathrm{O} 1$ & $\mathrm{O} 2$ & $\mathrm{O} 3$ \\
\hline Beijing & 6954 & 4750 & 1962 & 13723 & 269 \\
\hline Tianjin & 6818 & 7686 & 1299 & 9720 & 589 \\
\hline Hebei & 27531 & 56234 & 7194 & 20255 & 1993 \\
\hline Shanxi & 16808 & 35190 & 3574 & 8529 & 2151 \\
\hline Inner Mongolia & 16820 & 27488 & 2472 & 11981 & 2489 \\
\hline Liaoning & 20947 & 26955 & 4375 & 18263 & 1295 \\
\hline Jilin & 8297 & 8240 & 2747 & 8684 & 605 \\
\hline Heilongjiang & 11234 & 10111 & 3833 & 9950 & 777 \\
\hline Shanghai & 11201 & 12969 & 2303 & 17959 & 876 \\
\hline Jiangsu & 25774 & 31213 & 7869 & 40516 & 3359 \\
\hline Zhejiang & 16865 & 20434 & 5447 & 27154 & 2568 \\
\hline Anhui & 9707 & 17849 & 5957 & 12120 & 1444 \\
\hline Fujian & 9809 & 13507 & 3693 & 14369 & 1356 \\
\hline Jiangxi & 6355 & 9812 & 4462 & 9433 & 664 \\
\hline Shandong & 34808 & 43837 & 9588 & 39787 & 3043 \\
\hline Henan & 21438 & 22709 & 9405 & 22619 & 2192 \\
\hline Hubei & 15138 & 13865 & 5728 & 15638 & 2043 \\
\hline Hunan & 14880 & 14673 & 6570 & 15245 & 1226 \\
\hline Guangdong & 26908 & 24092 & 10441 & 45963 & 3237 \\
\hline Guangxi & 7919 & 14520 & 4610 & 8910 & 1032 \\
\hline Hainan & 1359 & 1360 & 869 & 2105 & 153 \\
\hline Chongqing & 7856 & 10943 & 2885 & 8562 & 504 \\
\hline Sichuan & 17892 & 20107 & 8045 & 16745 & 1795 \\
\hline Guizhou & 8175 & 10192 & 3479 & 4421 & 1386 \\
\hline Yunnan & 8674 & 10978 & 4602 & 7336 & 1365 \\
\hline Shaanxi & 8882 & 13510 & 3735 & 10285 & 1112 \\
\hline Gansu & 5923 & 6252 & 2560 & 3810 & 792 \\
\hline Qinghai & 2568 & 3952 & 563 & 1250 & 468 \\
\hline Ningxia & 3681 & 16324 & 633 & 1610 & 587 \\
\hline Xinjiang & 8290 & 9310 & 2185 & 565 & 679 \\
\hline
\end{tabular}

a greater contribution to the stabilization of the country. Therefore, it is considered an output.

Output 2 (O2). Gross domestic product (GDP, 100 million): GDP is one of direct outputs in productive process, and it is one of important indicators to evaluate the performance of DMUs. Accordingly, it is selected as an output.

Output 3 (O3). Power generation by region (100 million $\mathrm{kWh}$ ): power generation is another important product in productive process. If it is selected as an output, it could encourage DMUs who want to improve their environmental contributions to improve their technologies.

In addition, the total TEP allocation proportion is 1 . Suppose that the optimal TEP allocation proportion is $\left(P_{j}^{*}, \forall j\right)$; then the optimal TEP allocation plan would be $\left(R_{j}^{*}=R \times\right.$ $\left.P_{j}^{*}, \forall j\right)$, where $R$ is the total quotas of the allocated TEP, and the TEP allocated to $\mathrm{DMU}_{j}$ is denoted by $R_{j}(j=1, \ldots, n)$.

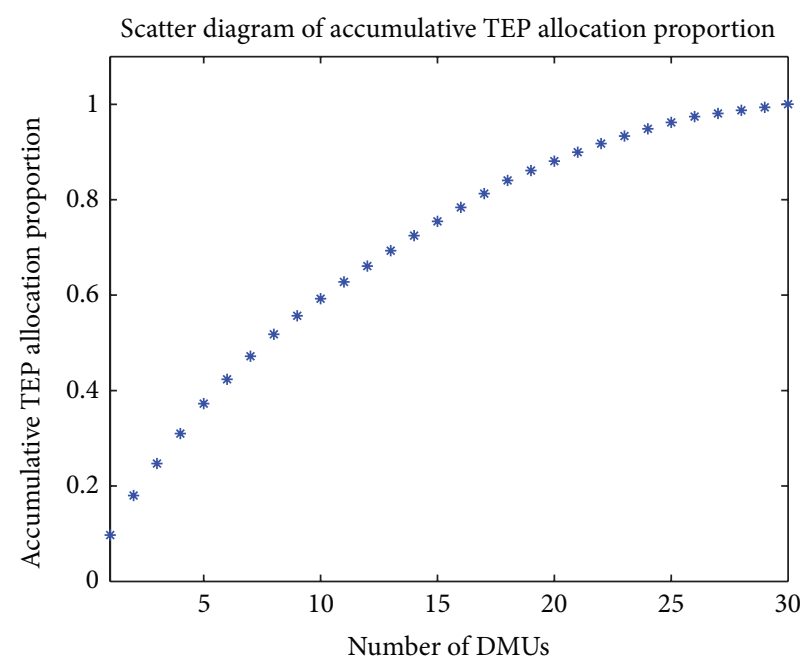

FIgURE 1: The accumulative TEP allocation proportion.

3.2. Results and Analyses. As shown in Table 1, the data set of 30 provincial administrative regions in China is from China energy statistical yearbook (2011). Because some data of Tibet, Taiwan, Hong Kong, and Macao are unavailable, we omit them here.

Applying our approach into the data set in Table 1, we can obtain relevant computational results as given in Table 2 . Based on model (4), we can get the TEP allocation interval as shown in the third column of Table 2. The optimal allocation proportion must be generated in the interval. We can find that the allocation interval can reflect the scales of DMUs. For example, all indicator values of Zhejiang are larger than that of Beijing, which means that the scale of Zhejiang is larger than that of Beijing. Consequently, the maximum allocation proportion of Beijing is smaller than the minimum proportion of Zhejiang.

From our proposed algorithm, we can obtain the optimal TEP allocation plan as shown in the second column of Table 2. It can be found that a DMU with a larger environmental contribution would be allocated a larger number of the TEP. For example, the quantity of energies consumed by Shanxi and Inner Mongolia is similar, but Inner Mongolia lets out less industrial waste gases and generates more GDP and more powers than those of Shanxi; only the number of population is less than that of Shanxi. Thus, on the whole, the environmental contribution of Inner Mongolia is more than that of Shanxi, and the TEP proportion allocated to Inner Mongolia (0.0316) is larger than Shanxi (0.0278). Similar examples are also Beijing and Tianjin, Heilongjiang and Shanghai, Yunnan and Shaanxi, and so on. Accordingly, our allocation approach can encourage DMUs to develop and apply low-carbon technologies to achieve the target of the energy consumption saving and emissions reduction.

To illustrate the TEP allocation plan more intuitive, as shown in Figure 1, we rearrange the TEP allocation proportion in a descending order and plot the accumulative TEP allocation proportion. It shows that the first five DMUs are allocated nearly 40 percents of the total amount of 
TABLE 2: Relevant computational results.

\begin{tabular}{|c|c|c|c|c|c|}
\hline \multirow{2}{*}{ Region } & \multirow{2}{*}{ TEP allocation proportion } & \multicolumn{2}{|c|}{ Allocation interval } & \multirow{2}{*}{ Satisfaction degree } & \multirow{2}{*}{$E_{j}$} \\
\hline & & minimum & maximum & & \\
\hline Beijing & 0.0135 & 0.0000 & 0.0342 & 0.3946 & 1.00 \\
\hline Tianjin & 0.0119 & 0.0000 & 0.0234 & 0.5092 & 1.00 \\
\hline Hebei & 0.0322 & 0.0000 & 0.0541 & 0.5957 & 1.00 \\
\hline Shanxi & 0.0278 & 0.0059 & 0.0556 & 0.4402 & 1.00 \\
\hline Inner Mongolia & 0.0316 & 0.0000 & 0.0704 & 0.4481 & 1.00 \\
\hline Liaoning & 0.0188 & 0.0000 & 0.0427 & 0.4394 & 1.00 \\
\hline Jilin & 0.0157 & 0.0062 & 0.0215 & 0.6210 & 1.00 \\
\hline Heilongjiang & 0.0195 & 0.0043 & 0.0305 & 0.5809 & 1.00 \\
\hline Shanghai & 0.0207 & 0.0015 & 0.0434 & 0.4576 & 1.00 \\
\hline Jiangsu & 0.0828 & 0.0538 & 0.1125 & 0.4935 & 1.00 \\
\hline Zhejiang & 0.0626 & 0.0391 & 0.0928 & 0.4367 & 1.00 \\
\hline Anhui & 0.0462 & 0.0279 & 0.0701 & 0.4343 & 1.00 \\
\hline Fujian & 0.0353 & 0.0277 & 0.0445 & 0.4508 & 1.00 \\
\hline Jiangxi & 0.0298 & 0.0134 & 0.0515 & 0.4324 & 1.00 \\
\hline Shandong & 0.0670 & 0.0458 & 0.0938 & 0.4431 & 1.00 \\
\hline Henan & 0.0631 & 0.0478 & 0.0865 & 0.3946 & 1.00 \\
\hline Hubei & 0.0482 & 0.0364 & 0.0662 & 0.3946 & 1.00 \\
\hline Hunan & 0.0386 & 0.0179 & 0.0581 & 0.5161 & 1.00 \\
\hline Guangdong & 0.0971 & 0.0770 & 0.1223 & 0.4450 & 1.00 \\
\hline Guangxi & 0.0330 & 0.0200 & 0.0517 & 0.4113 & 1.00 \\
\hline Hainan & 0.0063 & 0.0036 & 0.0098 & 0.4230 & 1.00 \\
\hline Chongqing & 0.0152 & 0.0018 & 0.0228 & 0.6400 & 1.00 \\
\hline Sichuan & 0.0510 & 0.0356 & 0.0746 & 0.3960 & 1.00 \\
\hline Guizhou & 0.0289 & 0.0096 & 0.0461 & 0.5277 & 1.00 \\
\hline Yunnan & 0.0360 & 0.0168 & 0.0525 & 0.5362 & 1.00 \\
\hline Shaanxi & 0.0294 & 0.0239 & 0.0353 & 0.4798 & 1.00 \\
\hline Gansu & 0.0182 & 0.0085 & 0.0262 & 0.5446 & 1.00 \\
\hline Qinghai & 0.0067 & 0.0012 & 0.0152 & 0.3978 & 1.00 \\
\hline Ningxia & 0.0065 & 0.0000 & 0.0165 & 0.3946 & 1.00 \\
\hline Xinjiang & 0.0065 & 0.0000 & 0.0164 & 0.3946 & 1.00 \\
\hline
\end{tabular}

the TEP. The first five DMUs are Guangdong, Jiangsu, Shandong, Henan, and Zhejiang. They have a common feature: big scale with advanced economy. On the other hand, some DMUs, such as Beijing and Shanghai, have advanced economies, but they are allocated a low TEP proportion due to their small scales.

The satisfaction degrees of DMUs are shown in the fourth column of Table 2. Intuitionally, the change range of satisfaction degrees is small, that is, $(0.3946,0.64)$. The mean and the standard deviation of satisfaction degrees are 0.4691 and 0.0719 , respectively. Thus, the dispersion degree of the satisfaction is quite small. The fairness of satisfaction degrees is to ensure the TEP allocation plan more acceptable.

The last column of Table 2 shows the environmental efficiency after the allocation, which is calculated by CCR DEA model [33]. From the DEA perspective, we can find that our allocation plan can ensure that all DMUs are efficient (i.e., the efficiency score is 1) under a common set of variable weights, which means that all DMUs can reach the production frontier simultaneously under our allocation plan.

\section{Conclusions}

This study proposes a TEP allocation approach based on the proportional allocation concept. Our proposed approach is different from traditional TEP allocation methods. We first define the environmental contribution of DMUs as their weighted sum outputs minus their weighted sum inputs and deduce a TEP allocation set based on the allocation rule that the TEP allocated to DMUs should be proportional to their environmental contribution. We then obtain the allocation intervals of DMUs and define the satisfaction degrees of DMUs as the coefficients of their convex combinations. Finally, we propose an algorithm based on the max-min fairness of satisfaction degrees to obtain a unique TEP allocation plan. Our allocation plan can not only consider the scales of DMUs but, more important, it can also provide motivations 
to DMUs to develop and use low-carbon technologies and achieve the low-carbon economy. Besides, the max-min fairness of satisfaction degrees can ensure that the generated TEP allocation plan is more acceptable. In addition, from the DEA perspective, the TEP allocation set can also ensure that both each DMU and the entire whole organization efficient are under a common set of variable weights.

In the future work, it might be interesting to extend our method to the dynamic allocation process.

\section{Conflict of Interests}

The authors declare that there is no conflict of interests regarding the publication of this paper.

\section{Acknowledgments}

This research is supported by the National Science Foundation of China for Distinguished Youth Scholars (no. 71225002), National Natural Science Foundation of China under Grants (nos. 61101219, 71271196, 61201050, and 21307150), Science Funds for Creative Research Groups of the National Natural Science Foundation of China and University of Science and Technology of China (nos. 71121061 and WK2040160008), and the Fund for International Cooperation and Exchange of the National Natural Science Foundation of China (Grant no. 71110107024).

\section{References}

[1] L. H. Goulder, "Effects of carbon taxes in an economy with prior tax distortions: an intertemporal general equilibrium analysis," Journal of Environmental Economics and Management, vol. 29, no. 31, pp. 271-297, 1995.

[2] Y. J. Bor and Y. Huang, "Energy taxation and the double dividend effect in Taiwan's energy conservation policy-an empirical study using a computable general equilibrium model," Energy Policy, vol. 38, no. 5, pp. 2086-2100, 2010.

[3] W. J. Baumol and W. E. Oates, The Theory of Environmental Policy, Cambridge University Press, New York, NY, USA, 2nd edition, 1988.

[4] A. D. Ellerman, "A note on tradeable permits," Environmental and Resource Economics, vol. 31, no. 2, pp. 123-131, 2005.

[5] A. Marciano, "Ronald Coase, "The Problem of Social Cost" and the Coase Theorem: an anniversary celebration," European Journal of Law and Economics, vol. 31, no. 1, pp. 1-9, 2011.

[6] S. Lozano, G. Villa, and R. Brännlund, "Centralised reallocation of emission permits using DEA," European Journal of Operational Research, vol. 193, no. 3, pp. 752-760, 2009.

[7] A. Dixit and M. Olson, "Does voluntary participation undermine the Coase Theorem?" Journal of Public Economics, vol. 76, no. 3, pp. 309-335, 2000.

[8] R. D. McKelvey and T. Page, "Taking the Coase Theorem seriously," Economics and Philosophy, vol. 15, no. 2, pp. 235-247, 1999.

[9] C. Boemare and P. Quirion, "Implementing greenhouse gas trading in Europe: lessons from economic literature and international experiences," Ecological Economics, vol. 43, no. 2-3, pp. 213-230, 2002.
[10] D. Burtraw and K. Palmer, "Compensation rules for climate policy in the electricity sector," Journal of Policy Analysis and Management, vol. 27, no. 4, pp. 819-847, 2008.

[11] D. Burtraw, D. Kahn, and K. Palmer, " $\mathrm{CO}_{2}$ allowance allocation in the Regional Greenhouse Gas Initiative and the effect on electricity investors," Electricity Journal, vol. 19, no. 2, pp. 79-90, 2006.

[12] L. Zetterberg, M. Wråke, T. Sterner, C. Fischer, and D. Burtraw, "Short-run allocation of emissions allowances and long-term goals for climate policy," Ambio, vol. 41, no. 1, pp. 23-32, 2012.

[13] M. Åhman, D. Burtraw, J. Kruger, and L. Zetterberg, "A TenYear Rule to guide the allocation of EU emission allowances," Energy Policy, vol. 35, no. 3, pp. 1718-1730, 2007.

[14] K. Neuhoff, K. Keats Martinez, and M. Sato, "Allocation, incentives and distortions: the impact of EU ETS emissions allowance allocations to the electricity sector," Climate Policy, vol. 6, no. 1, pp. 73-91, 2006.

[15] P. Cramton and S. Kerr, "Tradeable carbon permit auctions how and why to auction not grandfather," Energy Policy, vol. 30, no. 4, pp. 333-345, 2002.

[16] A. K. Kouakou, "Economic growth and electricity consumption in Cote d'Ivoire: evidence from time series analysis," Energy Policy, vol. 39, no. 6, pp. 3638-3644, 2011.

[17] C. Fischer, I. W. H. Parry, and W. A. Pizer, "Instrument choice for environmental protection when technological innovation is endogenous," Journal of Environmental Economics and Management, vol. 45, no. 3, pp. 523-545, 2003.

[18] K. Binmore and P. Klemperer, "The biggest auction ever: the sale of the British 3G telecom licences," Economic Journal, vol. 112, no. 478, pp. C74-C96, 2002.

[19] I. W. H. Parry, R. C. Williams III, and L. H. Goulder, "When can carbon abatement policies increase welfare? The fundamental role of distorted factor markets," Journal of Environmental Economics and Management, vol. 37, no. 1, pp. 52-84, 1999.

[20] A. Wefky, F. Espinosa, L. de Santiago, P. Revenga, J. L. Lazaro, and M. Martinez, "Electrical drive radiated emissions estimation in terms of input control using extreme learning machines," Mathematical Problems in Engineering, vol. 2012, Article ID 790526, 11 pages, 2012.

[21] A. M. Elaiw, X. Xia, and A. M. Shehata, "Minimization of fuel costs and gaseous emissions of electric power generation by model predictive control," Mathematical Problems in Engineering, vol. 2013, Article ID 906958, 15 pages, 2013.

[22] Y. Wei and B. Xin, "Governance mechanism for global greenhouse gas emissions: a stochastic differential game approach," Mathematical Problems in Engineering, vol. 2013, Article ID 312585, 13 pages, 2013.

[23] D. Bertsimas, V. F. Farias, and N. Trichakis, "The price of fairness," Operations Research, vol. 59, no. 1, pp. 17-31, 2011.

[24] X. Si, L. Liang, G. Jia, L. Yang, H. Wu, and Y. Li, "Proportional sharing and DEA in allocating the fixed cost," Applied Mathematics and Computation, vol. 219, no. 12, pp. 6580-6590, 2013.

[25] R. Lin, "Allocating fixed costs and common revenue via data envelopment analysis," Applied Mathematics and Computation, vol. 218, no. 7, pp. 3680-3688, 2011.

[26] G. R. Jahanshahloo, F. H. Lotfi, N. Shoja, and M. Sanei, "An alternative approach for equitable allocation of shared costs by using DEA," Applied Mathematics and Computation, vol. 153, no. 1, pp. 267-274, 2004.

[27] G. R. Jahanshahloo, F. H. Lotfi, and M. Moradi, "A DBA approach for fair allocation of common revenue," Applied 
Mathematics and Computation, vol. 160, no. 3, pp. 719-724, 2005.

[28] Y. Li, M. Yang, Y. Chen, Q. Dai, and L. Liang, "Allocating a fixed cost based on data envelopment analysis and satisfaction degree," Omega, vol. 41, no. 1, pp. 55-60, 2013.

[29] A. Charnes, W. W. Cooper, and E. Rhodes, "Measuring the efficiency of decision making units," European Journal of Operational Research, vol. 2, no. 6, pp. 429-444, 1978.

[30] W. D. Cook and J. Zhu, "Allocation of shared costs among decision making units: a DEA approach," Computers and Operations Research, vol. 32, no. 8, pp. 2171-2178, 2005.

[31] W. D. Cook and M. Kress, "Characterizing an equitable allocation of shared costs: a DEA approach," European Journal of Operational Research, vol. 119, no. 3, pp. 652-661, 1999.

[32] J. E. Beasley, "Allocating fixed costs and resources via data envelopment analysis," European Journal of Operational Research, vol. 147, no. 1, pp. 198-216, 2003.

[33] Y. Li, F. Yang, L. Liang, and Z. Hua, "Allocating the fixed cost as a complement of other cost inputs: a DEA approach," European Journal of Operational Research, vol. 197, no. 1, pp. 389-401, 2009.

[34] J. T. Pastor, J. L. Ruiz, and I. Sirvent, "A statistical test for nested radial DEA models," Operations Research, vol. 50, no. 4, pp. 728735, 2002. 


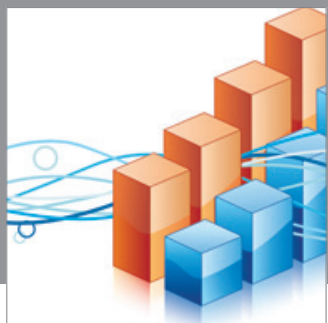

Advances in

Operations Research

mansans

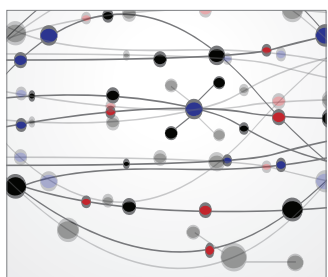

The Scientific World Journal
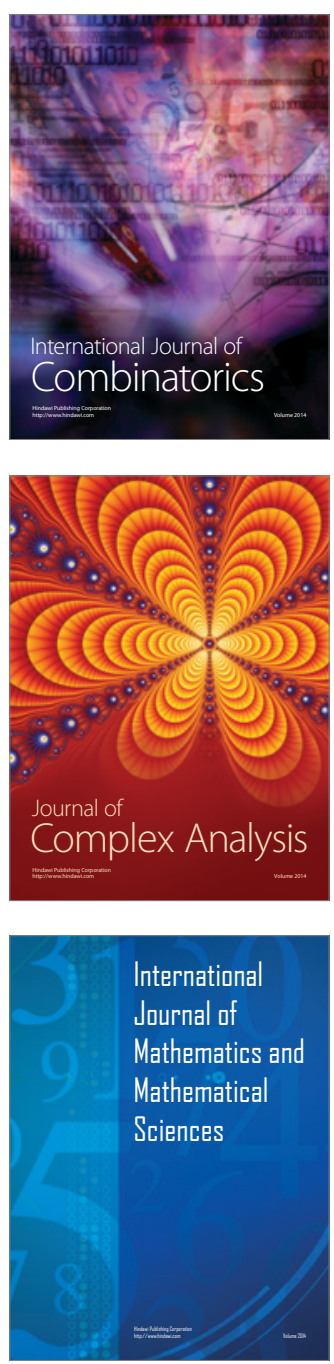
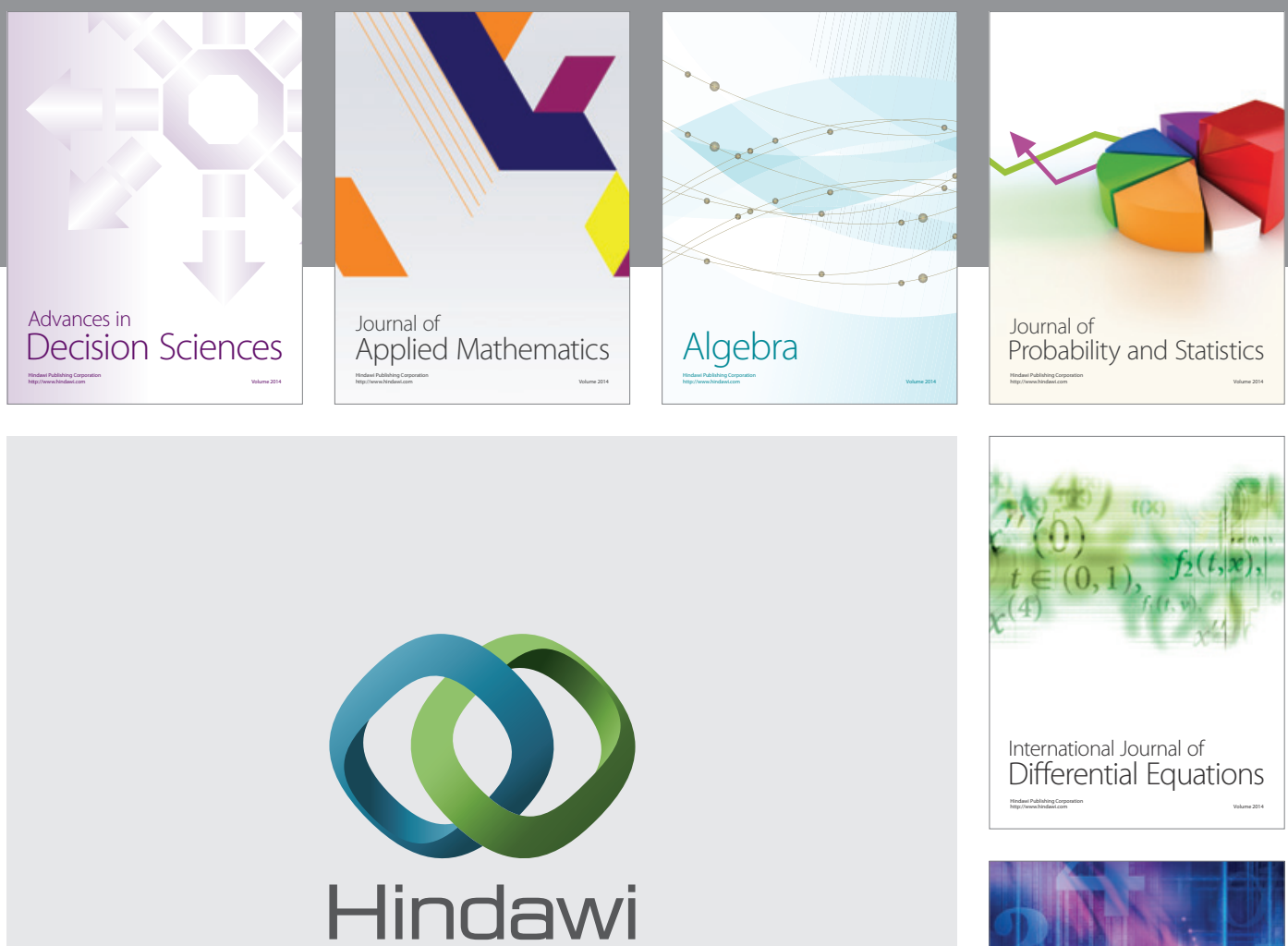

Submit your manuscripts at http://www.hindawi.com
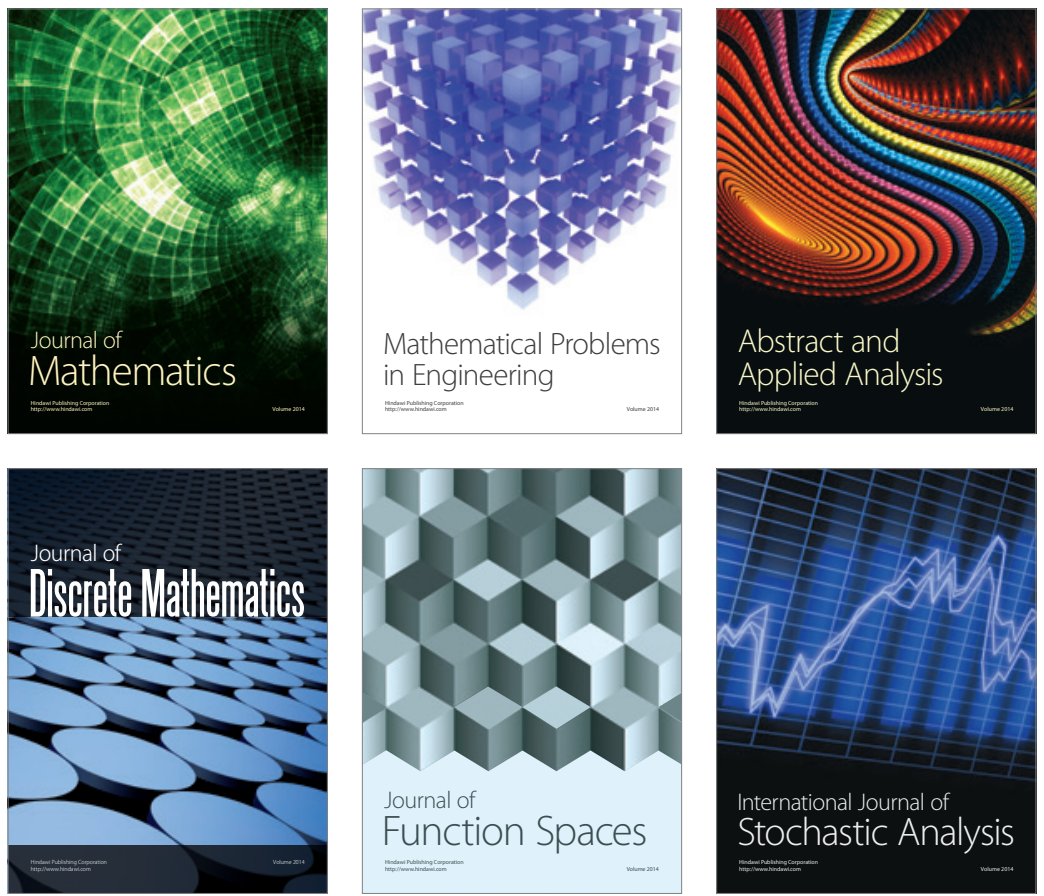

Journal of

Function Spaces

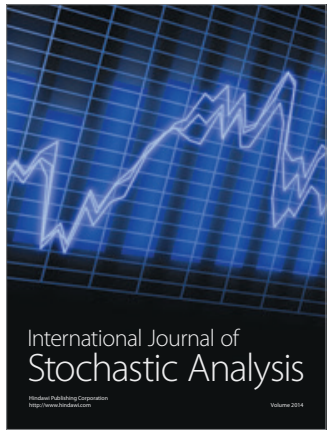

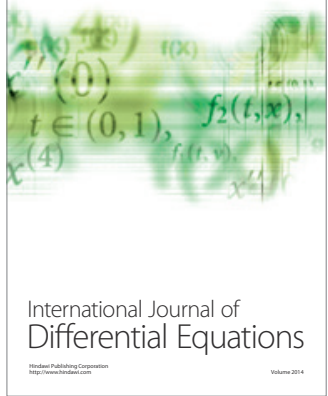
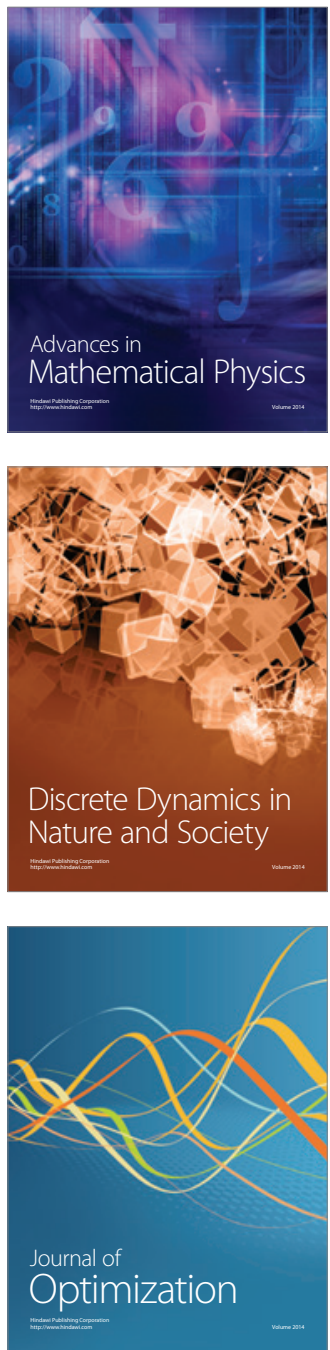